\title{
Skeletal Muscle microRNAs: Roles in Differentiation, Disease and Exercise
}

\author{
Rasmus J. O. Sjögren, Magnus H. L. Lindgren Niss, and Anna Krook
}

\begin{abstract}
MicroRNAs (miRNA) are a noncoding RNA species that play important roles in the regulation of gene expression. Since miRNAs are able to target multiple genes simultaneously, miRNAs provide a mechanism for efficiently modulating a whole pathway to change or alter the functional properties in a particular target tissue. Ablation of miRNA processing specifically in skeletal muscle results in muscle abnormalities and perinatal death, underscoring that miRNAs control essential processes in skeletal muscle development and function. In this chapter we summarise current knowledge on miRNAs involved in skeletal muscle differentiation, disease and exercise.
\end{abstract}

\section{Discovery and Biological Role of miRNAs}

Precise control of gene expression and hence transcriptional regulation is a prerequisite for maintaining cellular functions, including growth and metabolic homeostasis. Several epigenetic factors, including DNA methylation, histone modification and miRNAs play important roles in gene expression in multicellular organisms. miRNAs were first described at the beginning of the 1990s, when it was appreciated that these short single-stranded non-coding RNAs function to post-transcriptionally regulate mRNA abundance and protein translation. Lin-4 and let-7 were the first miRNAs to be identified and found to be involved in the regulation of larval development of $C$. elegans (Lee et al. 1993; Wightman et al. 1993; Reinhart et al. 2000). miRNAs have since been observed in viruses, plants and mammals (Bartel 2009) and found to regulate a wide variety of cellular functions, including proliferation, differentiation and metabolism (He et al. 2007b; Williams et al. 2009a; Massart et al. 2016).

\footnotetext{
R. J. O. Sjögren

Department of Molecular Medicine and Surgery, Karolinska Institutet, Stockholm, Sweden

M. H. L. Lindgren Niss $\bullet$ A. Krook $(\varangle)$

Department of Physiology and Pharmacology, Integrative Physiology, Karolinska Institutet, Stockholm, Sweden

e-mail: anna.krook@ki.se
} 


\section{miRNA Biogenesis, mRNA Interaction and Target Prediction}

miRNAs are expressed in the nucleus as primary-miRNA (pri-miRNA) transcripts, which require processing before becoming functional miRNAs. Pri-miRNAs contain stem-loop structures that are recognized and cleaved by the RNase III endonuclease Drosha to form precursor miRNAs (pre-miRNAs; Lee et al. 2003). The pre-miRNA is then transported to the cytoplasm, where it is subsequently processed by RNase III Dicer into a mature miRNA of approximately 21 nucleotides (Hutvagner et al. 2001). The mature miRNA is then incorporated into the RNA-induced silencing complex (RISC), where mRNA target interaction takes place (Hammond et al. 2000). The canonical model of miRNA-mRNA interaction occurs by perfect or partial pairing at the $5^{\prime}$-end of the miRNA to a complementary site of the $3^{\prime}$ UTR of the target. A sequence of 6-8 nucleotides at the $5^{\prime}$ end of the miRNA, called the seed region, guides the RISC complex to targeted mRNAs. Repression of mRNAs may then occur by inhibition of translation or by degradation of the transcript, ultimately reducing protein abundance of targeted genes (Melo and Melo 2014).

A key challenge in miRNA research to date involves identifying the target genes for each miRNA. The seed is a dominant motif in miRNAs and is, therefore, used in prediction algorithms to identify potential targets. The algorithms are centred on finding complementary sequences in the $3^{\prime}$ UTR of mRNAs. Evolutionary conservation of the complementary sequence is also taken into consideration, and whether there is a supplementary pairing site in the $3^{\prime}$ part of the miRNA (for review, see Bartel 2009). However, at present the prediction algorithms have been only partially accurate in identifying true target sites, yielding both false positive and false negative predictions. When comparing results from silencing and over-expression experiments, only a small percentage of mRNA targets were found to be affected by both (Nicolas et al. 2008). Of these, approximately half had a sequence in the $3^{\prime}$-UTR matching the seed, but none was found by prediction programs (Nicolas et al. 2008). Since miRNAs exert their function both at the level of mRNA abundance and at protein abundance, transcriptomic analysis will miss targets that are regulated only at the protein level. To further add to the complexity of miRNA regulation, one gene may be targeted by several different miRNAs. Additionally, the same miRNA may have several target sites on the same gene (Bartel 2009). One miRNA may even have opposing effects on a target gene in different tissues (Lu et al. 2010; Chuang et al. 2015).

\section{Role of miRNAs in the Regulation of Skeletal Muscle Development}

\section{Skeletal Muscle Development and Regeneration}

Skeletal muscle has been shown to express several RNA species (Gallagher et al. 2010), and dysregulation of skeletal muscle miRNAs has been implicated in a number of different disease states (Williams et al. 2009a; Massart et al. 2016). Skeletal 
muscle has a large adaptive potential in response to contractile activity. This plasticity is necessary to modify contractile features and adapt metabolic capacity to new requirements following endurance and/or resistance exercise. Skeletal muscle also has a high regenerative capacity in response to injury or damage. Critical to this plasticity and the regenerative potential of skeletal muscle are myogenic progenitor cells, termed satellite cells (Dumont et al. 2015). In adults, satellite cells are quiescent but they can, in response to injury or increased contractile activity, re-enter the cell cycle and proliferate and thereafter differentiate, fuse, and regenerate myofibres.

Skeletal muscle development has been studied extensively in vitro through isolation, growth and differentiation of satellite cells and in vivo during embryogenesis (see Fig. 1). Molecular regulation of cell determination to the myogenic lineage and proliferation of these cells involves the paired box transcription factors PAX3 and PAX7 (Braun and Gautel 2011). Pax3 loss-of-function during embryogenesis in mice results in the absence of musculature in the trunk region due to reduced migration of satellite cells (Bober et al. 1994; Tremblay et al. 1998). While Pax7 deletion in animals has little effect on embryogenic muscle formation (Oustanina et al. 2004), it is essential for satellite cell formation and adult myogenesis (Sambasivan et al. 2011). When activated, satellite cells can migrate and re-enter the cell cycle to start proliferation. The processes of satellite cell commitment and differentiation into multinucleated myotubes are controlled by a group of basic helix-loop-helix transcription factors known as myogenic regulatory factors (MRFs). The MRFs consist of four members: myogenic factor 5 (MYF5), myogenic differentiation 1 (MYOD1), myogenin (MYOG), and myogenic regulatory factor 4 (MRF4). These transcription factors promote terminal differentiation by regulating the expression of several myogenic genes (Braun and Gautel 2011). Satellite cells committed to the myogenic program and myogenesis are termed myoblasts, which typically express PAX7 and early MRFs such as MYOD and MYF5. Expression of these early MRFs is crucial for myoblast maturation because a combined Myod and Myf5 loss-offunction results in the absence of skeletal muscle formation during embryogenesis (Rudnicki et al. 1993). MYF5 and MYOD are considered determination factors required for establishment of myogenic identity since they are upstream transcriptional regulators of late MRFs, MYOG and MRF4 (Braun and Gautel 2011). Myoblasts will leave the cell cycle for terminal differentiation by lowering PAX7 and MYF5 expression while inducing the late MRFs. The late MRFs are important for terminal differentiation, and lack of, for example, Myog in mice leads to postnatal lethality due to muscle deficiency (Hasty et al. 1993).

\section{miRNA Regulation of Myogenesis In vitro and In vivo}

miRNAs are important regulators of cell proliferation and differentiation, processes that are critical to proper tissue development and maintenance. The relative expression of miRNAs is tissue dependent, with several miRNAs showing enrichment in skeletal muscle (and heart muscle). These muscle-enriched miRNAs are termed 


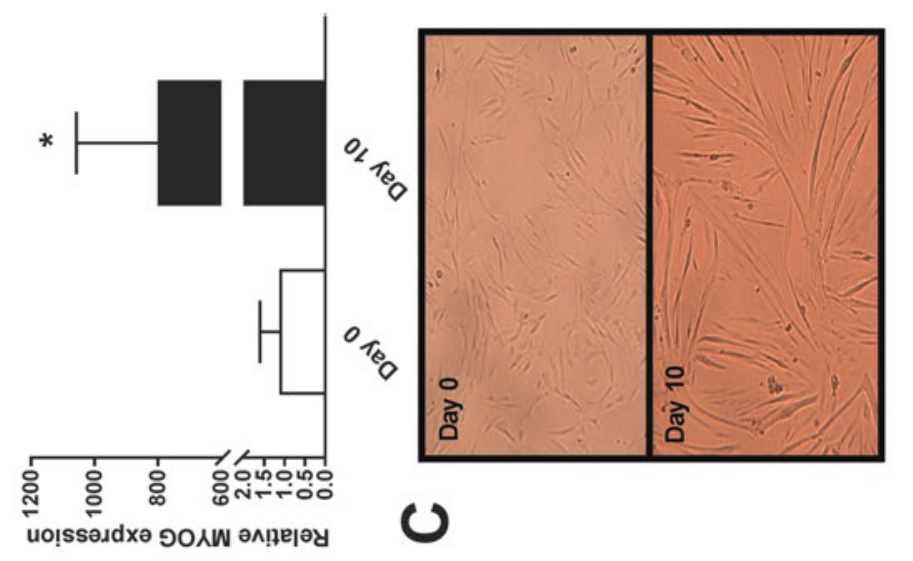

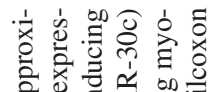

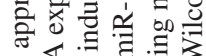
局苋氞完

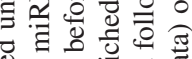
可氜 过 纪它总.。

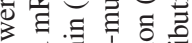

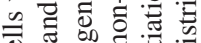
8 - 0 ๑ 导灾氖

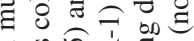

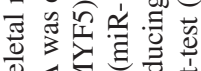

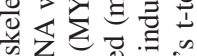

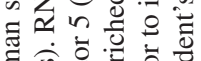

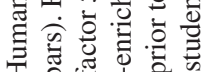
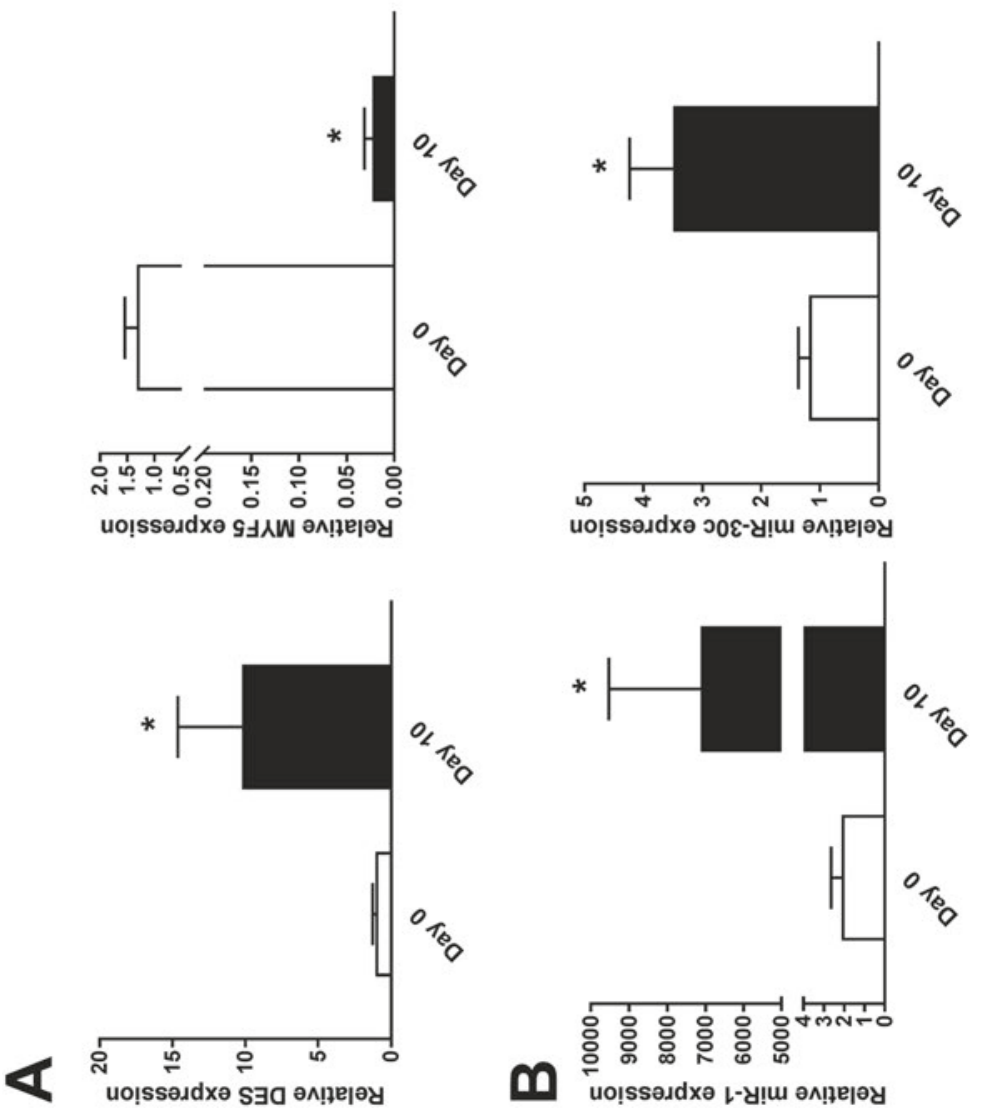

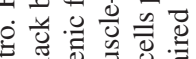

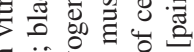

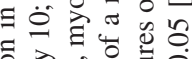

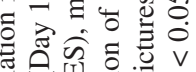

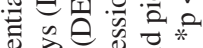

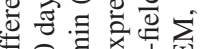

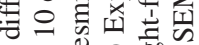
=

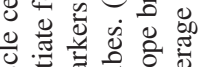

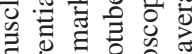

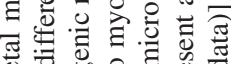

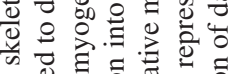

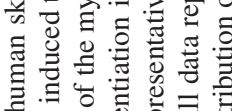

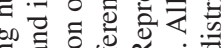
䠉

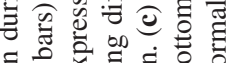

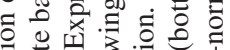

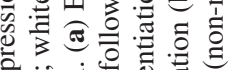
केष्

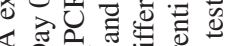
艺

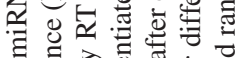

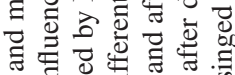
ส

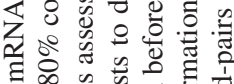

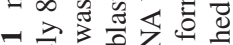

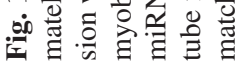


"myomiRs" (Sempere et al. 2004). Some members of the myomiRs are organized in bicistronic clusters with genomic colocalisation of miR-1-1/miR-133a-2, miR1-2/miR-133a-1 and miR-133b/206. Thus, these miRNAs share similar expression patterns and are induced during skeletal muscle cell differentiation by upstream transcriptional regulation of different MRF members, including MYOD and MYOG (Rao et al. 2006; Sweetman et al. 2008). Besides sharing similar regulation of expression, they also share similar sequences. For example, miR-133a-1/2 (identical sequences) and miR-133b differ by only one single nucleotide outside of the seed region, and miR-1-1/2 (identical sequences) and miR-206 differ in four nucleotides at the $3^{\prime}$ end but share identical seed sequences in humans. Thus, miR-1 and miR-206, and miR-133a and miR-133b, respectively, regulate a set of similar, but not identical, target genes.

The aforementioned myomiRs are all potent regulators of satellite cell differentiation and proliferation. miR-1 and miR-206 are induced upon satellite cell commitment and differentiation, and increased expression promotes differentiation of these cells (Fig. 1; Chen et al. 2006; Kim et al. 2006). miR-1 and miR-206 induce differentiation by targeting several repressors of skeletal muscle cell differentiation, including histone deacetylase 4 (Hdac4); Chen et al. 2006; Williams et al. 2009b), Pax3 (Goljanek-Whysall et al. 2011) and Pax7 (Chen et al. 2010). The effects of $\mathrm{miR}-133 \mathrm{a} / \mathrm{b}$ on myogenesis are still debated. It is clear that miR-133, like several other myomiRs, is induced during skeletal muscle differentiation (Chen et al. 2006; Kim et al. 2006), whereas different effects of miR-133 on the myogenic process have been reported. Initial observations have indicated that miR-133 promotes the proliferative state of myoblasts by repressing Serum Response Factor (Srf; Chen et al. 2006). More recent evidence suggests that miR-133 instead functions by inhibiting myoblast proliferation to promote muscle cell differentiation (Zhang et al. 2012; Feng et al. 2013). These effects of miR-133 are due to targeting of proproliferative target genes. Such targets include SP1 transcription factor (Sp1), an upstream regulator of Cyclin D1 expression, and Fibroblast Growth Factor Receptor 1 (Fgfr1) and Protein Phosphatase 2 Catalytic Subunit Alpha (Pp2ac), which are important for regulation of ERK1/2 phosphorylation status (Zhang et al. 2012; Feng et al. 2013). The differences in results noted could indicate that miR-133 can influence both proliferation and differentiation in a context-dependent manner.

While the effects of miR-1 and miR-206 on skeletal muscle cell differentiation in vitro are clear, ablation of miR-1-2 or miR-206 in mice did not result in disturbed skeletal muscle development during embryogenesis in vivo (Zhao et al. 2007; Williams et al. 2009b). Nevertheless, genetic deletion of miR-206 negatively affected post-embryonic regeneration of muscle and neuromuscular connections following injury (Williams et al. 2009b; Liu et al. 2012). Furthermore, miR-206 deletion exacerbated the dystrophic phenotype in a mouse model of muscular dystrophy (Liu et al. 2012). Contrary to these results, deletion of the miR-206/miR$133 \mathrm{~b}$ cluster was found not to be required for proper muscle regeneration (Boettger et al. 2014). These differences, and the absence of a robust phenotype following myomiR loss-of-function during embryogenesis, could be explained by the large redundancy in this group of myomiRs. Not only are there several genomic copies of 
miR-1 and miR-133a, but they also share similar sequences with miR-206 and miR$133 \mathrm{~b}$, respectively. Thus, miR-1 and miR-133a could compensate for the loss of miR-206/133b expression (Boettger et al. 2014). In contrast, D. melanogaster has only one genomic copy of miR-1 and, in this context, the absence of miR-206 is coincident with severely deformed musculature in miR-1 mutant larvae (Sokol and Ambros 2005), implicating that the presence of several genomic copies, as found in other species, provides system redundancy. Furthermore, a double knockout of miR-133a-1 and miR-133a-2 in mice resulted in cardiomyopathy and lethal defects in approximately $50 \%$ of offspring, whereas mice lacking only miR-133a-1 or miR133a-2 did not show this phenotype (Liu et al. 2008). The miR-133a double knockout mice that survived until adulthood also showed skeletal muscle defects, including mitochondrial dysfunction and centronuclear myopathy of type II fibres (Liu et al. 2011).

Skeletal muscle-specific Dicer ablation in mice results in reduced musclespecific miRNA expression and perinatal death, abnormal muscle morphology and reduced skeletal muscle mass (O'Rourke et al. 2007), indicating that proper miRNA maturation is essential for overall muscle function and development. Conditional knockout of Dicer in satellite cells in adult mice results in satellite cells exiting quiescence and entering the cell cycle, leading to severely impaired regeneration following skeletal muscle injury (Cheung et al. 2012). Collectively, evidence points towards a central function of miRNAs, not only for normal embryonic skeletal muscle biogenesis but also for adult muscle function and repair.

Not only is the expression of several myomiRs altered in response to satellite cell expansion and differentiation, but also several non-muscle enriched miRNAs are temporally regulated in expression during muscle cell differentiation (see Fig. 1). Several studies have determined miRNA expression profiles during differentiation in vitro and during myogenesis in vivo (Chen et al. 2011; Cheung et al. 2012; Koning et al. 2012; Dmitriev et al. 2013; Sjögren et al. 2015). We identified 44 miRNAs, including the canonical myomiRs, to be altered during primary human skeletal muscle cell differentiation (Sjögren et al. 2015), comparable to the 60 miRNAs altered in a similar study (Dmitriev et al. 2013). Nevertheless, these miRNAs might not influence either the proliferation or differentiation process but may be involved in other phenotypic changes associated with muscle cell differentiation, such as metabolism, hypertrophy or mitochondrial function. Examples of non-muscleenriched miRNAs identified to have altered expression and directly affecting proliferation or differentiation of skeletal muscle cells include, for example, miR-26a (Dey et al. 2012), miR-30 (Fig. 1; Guess et al. 2015) and miR-199a-5p (Alexander et al. 2013). Future studies are required to determine the targets and effects on skeletal muscle cell proliferation and differentiation, both in vivo and in vitro, of several of the miRNAs that have altered expression during satellite cell activation and differentiation. 


\section{Skeletal Muscle miRNA in Metabolic Disease}

Approximately half of the total body mass in healthy individuals consists of skeletal muscle, representing a substantial part of whole-body metabolism (DeFronzo and Tripathy 2009). Skeletal muscle also represents a primary target for insulin-mediated glucose disposal, and skeletal muscle insulin resistance is a characteristic feature in type 2 diabetes and in conditions of impaired glucose metabolism transport activity (Krook et al. 2000; Ryder et al. 2000). Furthermore, skeletal muscle function is crucial for proper posturing and locomotion patterns, and disruption in metabolic or motile functionality may greatly decrease an individual's quality of life. While there is good evidence that miRNAs play a key role in the regulation of muscle growth and differentiation, dysregulation of skeletal muscle miRNA expression in disease states has been less well studied, in particular in human cohorts.

Several miRNAs were found to be downregulated in response to a 3 -h euglycaemic-hyperinsulinaemic clamp in human skeletal muscle, including miR-1 and miR-133a (Granjon et al. 2009). Expression profiles of skeletal muscle miRNAs have been reported in a number of different rodent models of obesity and diabetes, including Goto-Kakizaki (GK) rats, a non-obese spontaneous T2D model (He et al. 2007a; Huang et al. 2009; Herrera et al. 2010), rats rendered diabetic by a combination of high fat diet and a low dose of streptozotocin (Karolina et al. 2011), as well as mice fed a high fat diet (Chen et al. 2012; Mohamed et al. 2014). These different models share skeletal muscle insulin resistance as a key characteristic. When miRNA profiles from patients with type 2 diabetes were compared against these different animal models, eight upregulated miRNAs found in type 2 diabetic patients were also found to be upregulated in at least one of the rodent arrays (for review and analysis, see Massart et al. 2016). Similarly, 16 of the downregulated miRNAs were recapitulated in rodent studies. Interestingly, two thirds of the commonly regulated miRNAs have been identified in mice rendered insulin resistant in response to a high fat diet (Massart et al. 2016). However, different miRNAs showed altered expression depending on the model. For example, miR-99a and miR-100, which were downregulated in skeletal muscle from patients with type 2 diabetes and in mice fed a high fat diet, were upregulated in rats on a high fat diet rendered diabetic with streptozotocin, suggesting that the aetiology of the insulin resistance influenced the miRNA expression signature. As yet, only a few of these miRNAs have been studied in vitro and/or in vivo in relation to metabolic disease, and their targets remain poorly characterized.

\section{Skeletal Muscle miRNAs in Response to Exercise}

Skeletal muscle responds rapidly to exercise, and even a single bout of acute exercise is sufficient to induce changes in gene expression. In response to many bouts of acute exercise, i.e., exercise training, skeletal muscle adapts by altering protein 
production, which impacts the functional as well as the metabolic properties of the exercised muscle. The inter-individual variability in skeletal muscle hypertrophic response to resistance exercise has been attributed to variations in the ability of satellite cell mobilization to proliferate and subsequent fuse with existing muscle fibres (Petrella et al. 2006, 2008). As detailed above, several miRNAs regulate skeletal muscle satellite cell quiescence, activation and differentiation, indicating potential roles for these miRNAs in skeletal muscle hypertrophy.

Identification of pathways and molecular mechanisms regulating skeletal muscle exercise adaptation has been a key focus from a number of different angles; from probing understanding of athletic performance to alterations relevant for metabolic disease. Different modes of exercise training lead to different adaptive responses; for example, strength training leads to more hypertrophic responses whereas aerobic exercise increases endurance. These differences are also mirrored in the different intracellular signalling pathways that are activated (for review, see Egan and Zierath 2013). Several lines of evidence suggest an important role for miRNAs in skeletal muscle development and hypertrophy (for review see Zacharewicz et al. 2013; Kovanda et al. 2014).

Several human studies have reported that short exercise bouts/training duration lead to increased skeletal muscle expression of miR-1 (Nielsen et al. 2010; Russell et al. 2013), whereas longer endurance training protocols lead to miR-1 downregulation (Nielsen et al. 2010; Drummond et al. 2011; Keller et al. 2011). Rodent studies are in general agreement regarding regulation of myomiRs in response to exercise (for review see Zacharewicz et al. 2013). In contrast, although several of the classical myomiRs have been noted to respond to exercise, a clear consensus has yet to emerge regarding which other miRNAs are regulated in response to exercise. These inconsistencies in the literature may be due to species differences as well as differences in the exercise protocols used, but they may even depend on different RNA extraction protocols (for more in depth discussion see Zacharewicz et al. 2013).

\section{miRNA Regulation of Skeletal Muscle Atrophy and During States of Muscle Mass Loss}

Skeletal muscle is the largest organ in adult mammals and muscle function is critical to metabolic homeostasis and health across the whole life span. Loss of skeletal muscle mass (atrophy) and function, also referred to as sarcopenia, occurs with aging (Cartee et al. 2016). Muscle loss is also noted in obese individuals, a phenomenon known as sarcopenic obesity, and is associated with lowered skeletal muscle insulin sensitivity. In addition, individuals with cancer, HIV-AIDS, chronic heart failure, chronic obstructive pulmonary disease, renal failure, rheumatoid arthritis, and osteoarthritis can all experience a dramatic loss of muscle mass (Wolfe 2006). Thus understanding the regulation of skeletal muscle mass and function is of clinical relevance. 
Three members of the myomiR family, miR-208a, miR-208b and miR-499, are encoded and expressed from sequences embedded within heart- and skeletal muscleenriched myosin genes, MYH6, MYH7 and MYH7B, respectively (van Rooij et al. 2009). miR-208a is exclusively expressed in heart muscle, whereas miR-208b and miR-499 are expressed both in heart muscle and in type I (oxidative) skeletal muscle fibres. Loss of function of both miR-208b and miR-499 in mice results in loss of type I fibres and is associated with increased expression of miR-208b and miR-499 pro-atrophic target genes, including purine rich element binding protein beta (Purb) and SRY-box containing gene 6 (Sox6; van Rooij et al. 2009). Furthermore, four weeks of hind limb suspension, resulting in severe skeletal muscle atrophy, reduces expression of miR-208b and miR-499 in rat skeletal muscle (McCarthy et al. 2009). In humans with skeletal muscle loss due to spinal cord injury, expression of miR$208 \mathrm{~b}$ and miR-499-5p is reduced and inversely related to expression of myostatin, a critical regulator of skeletal muscle mass (Boon et al. 2015). These miRNAs also participate in a transcriptional network together with estrogen-related receptors (ERRs) and members of the peroxisome proliferator activated receptor (PPAR) family to coordinate the regulation of skeletal muscle energy metabolism and fibre type specification (Gan et al. 2013).

Muscular dystrophy is characterized by muscle atrophy and weakness. A large microarray-based study found expression of 185 miRNAs to be altered in skeletal muscle in at least one of 10 common muscular disorders, including Duchenne muscular dystrophy (DMD; Eisenberg et al. 2007). Several miRNAs have been noted to be dysregulated both in human Duchenne muscular dystrophy and in a mouse model of the disease (Greco et al. 2009). Examples of dysregulated miRNAs include miR206, which was upregulated in states of muscular dystrophy (McCarthy et al. 2007; Greco et al. 2009), potentially due to constant regenerative processes in dystrophic skeletal muscle. However, as mentioned above, mice lacking miR-206 have a muscle dystrophic phenotype (Liu et al. 2012), underscoring the complexity of miRNA regulation. In the case of muscular dystrophy, a number of miRNAs has been proposed to have possible therapeutic potential. For example, overexpression of miR486, another muscle-enriched miRNA with decreased expression in muscle dystrophy (Eisenberg et al. 2007), improved muscle function in a mouse model of muscle dystrophy (Alexander et al. 2014). Another example is miR-431, where transgenic miR-431 mice with muscular dystrophy have improved skeletal muscle fatigability and force generation, potentially due to improved muscle regeneration and enhanced muscle cell differentiation capacity in vitro (Wu et al. 2015).

miRNAs are also potent regulators of signalling pathways known to regulate muscle atrophy. Two critical regulators of skeletal muscle atrophy are F-box Protein 32 [FBXO32; also known as Muscle atrophy F-box (MAFbx)] and Tripartite Motif Containing 63 [TRIM63; also known as Muscle RING finger 1 (MuRF1)], which regulate protein degradation through regulation of ubiquitination. The family of Forkhead Box O (FOXO) transcription factors, especially FOXO1 and FOXO3, are strong upstream regulators of both these genes during skeletal muscle atrophy (Glass 2010). FOXO1 activity was reduced following miR-486 overexpression in skeletal muscle cells in vitro, both through decreased FOXO1 expression and through increased FOXO1 phosphorylation (inhibitory) through direct miR-486- 
targeting of Phosphatase and Tensin Homolog (PTEN), a negative regulator of FOXO1-upstream kinase AKT (Xu et al. 2012). miR-486 overexpression also reduced induction of FOXO1 targets MAFbx and MuRF-1 protein expression in primary mouse muscle cells following treatment with dexamethasone, a potent inducer of muscle atrophy (Xu et al. 2012). In addition, overexpression of miR-486 protected against skeletal muscle loss in a mouse model of chronic kidney disease (Xu et al. 2012). Furthermore, miR-486 inhibition in vitro slightly reduced myotube diameter, and inhibition in vivo reduced the cross-sectional area of muscle fibres, confirming the effects of miR-486 on regulation of skeletal muscle mass (Hitachi et al. 2014). MAFbx and MuRF1 are also directly under miRNA-dependent regulation by two different miRNAs, miR-23a and miR-23b (Wada et al. 2011). miR-23a overexpression either in vitro or with a transgene in mouse skeletal muscle protected against dexamethasone-induced muscle atrophy (Wada et al. 2011). Cellular miR-23a is decreased in dexamethasone-induced skeletal muscle atrophy, potentially through a mechanism including enhanced exosomal release of miR-23a (Hudson et al. 2014).

miRNA expression has also been assessed following age or sarcopenia-induced skeletal muscle loss (Drummond et al. 2011; Rivas et al. 2014; Zacharewicz et al. 2014). Nevertheless, the overlap of miRNA signatures is small between these studies, potentially due to the small number of biological replicates in each study or due to different platforms to assess miRNA expression. Further studies will be needed to determine the impact of miRNA expression and regulation of target genes in human sarcopenia and muscle loss with ageing.

\section{Conclusions}

miRNAs are critical regulators of skeletal muscle function and play important roles in maintaining muscle function and regulating adaptation to different situations, including muscle use and disuse, as well as in different disease states. While the role of some of the classical myomiRs is increasingly appreciated and well understood, the challenge for the field lies in understanding not only the precise regulation of different miRNA species but also in dissecting and understanding the precise targets regulated by each miRNA or combination of miRNAs. Unravelling these molecular signatures could facilitate targeted and tissue-specific miRNA interventions in different disease states affecting skeletal muscle function and metabolism.

\section{References}

Alexander MS, Kawahara G, Motohashi N, Casar JC, Eisenberg I, Myers JA, Gasperini MJ, Estrella EA, Kho AT, Mitsuhashi S, Shapiro F, Kang PB, Kunkel LM (2013) MicroRNA-199a is induced in dystrophic muscle and affects WNT signaling, cell proliferation, and myogenic differentiation. Cell Death Differ 20:1194-1208 
Alexander MS, Casar JC, Motohashi N, Vieira NM, Eisenberg I, Marshall JL, Gasperini MJ, Lek A, Myers JA, Estrella EA, Kang PB, Shapiro F, Rahimov F, Kawahara G, Widrick JJ, Kunkel LM (2014) MicroRNA-486-dependent modulation of DOCK3/PTEN/AKT signaling pathways improves muscular dystrophy-associated symptoms. J Clin Invest 124:2651-2667

Bartel DP (2009) MicroRNAs: target recognition and regulatory functions. Cell 136:215-233

Bober E, Franz T, Arnold HH, Gruss P, Tremblay P (1994) Pax-3 is required for the development of limb muscles: a possible role for the migration of dermomyotomal muscle progenitor cells. Development 120:603-612

Boettger T, Wust S, Nolte H, Braun T (2014) The miR-206/133b cluster is dispensable for development, survival and regeneration of skeletal muscle. Skelet Muscle 4:23

Boon H, Sjögren RJ, Massart J, Egan B, Kostovski E, Iversen PO, Hjeltnes N, Chibalin AV, Widegren U, Zierath JR (2015) MicroRNA-208b progressively declines after spinal cord injury in humans and is inversely related to myostatin expression. Physiol Rep 3. pii: e12622

Braun T, Gautel M (2011) Transcriptional mechanisms regulating skeletal muscle differentiation, growth and homeostasis. Nat Rev Mol Cell Biol 12:349-361

Cartee GD, Hepple RT, Bamman MM, Zierath JR (2016) Exercise promotes healthy aging of skeletal muscle. Cell Metab 23:1034-1047

Chen JF, Mandel EM, Thomson JM, Wu Q, Callis TE, Hammond SM, Conlon FL, Wang DZ (2006) The role of microRNA-1 and microRNA-133 in skeletal muscle proliferation and differentiation. Nat Genet 38:228-233

Chen JF, Tao Y, Li J, Deng Z, Yan Z, Xiao X, Wang DZ (2010) microRNA-1 and microRNA-206 regulate skeletal muscle satellite cell proliferation and differentiation by repressing Pax7. J Cell Biol 190:867-879

Chen Y, Gelfond J, McManus LM, Shireman PK (2011) Temporal microRNA expression during in vitro myogenic progenitor cell proliferation and differentiation: regulation of proliferation by miR-682. Physiol Genomics 43:621-630

Chen GQ, Lian WJ, Wang GM, Wang S, Yang YQ, Zhao ZW (2012) Altered microRNA expression in skeletal muscle results from high-fat diet-induced insulin resistance in mice. Mol Med Rep 5:1362-1368

Cheung TH, Quach NL, Charville GW, Liu L, Park L, Edalati A, Yoo B, Hoang P, Rando TA (2012) Maintenance of muscle stem-cell quiescence by microRNA-489. Nature 482:524-528

Chuang TY, Wu HL, Chen CC, Gamboa GM, Layman LC, Diamond MP, Azziz R, Chen YH (2015) MicroRNA-223 expression is upregulated in insulin resistant human adipose tissue. J Diabet Res 2015:943659

DeFronzo RA, Tripathy D (2009) Skeletal muscle insulin resistance is the primary defect in type 2 diabetes. Diabetes Care 32(Suppl 2):S157-S163

Dey BK, Gagan J, Yan Z, Dutta A (2012) miR-26a is required for skeletal muscle differentiation and regeneration in mice. Genes Dev 26:2180-2191

Dmitriev P, Barat A, Polesskaya A, O'Connell MJ, Robert T, Dessen P, Walsh TA, Lazar V, Turki A, Carnac G, Laoudj-Chenivesse D, Lipinski M, Vassetzky YS (2013) Simultaneous miRNA and mRNA transcriptome profiling of human myoblasts reveals a novel set of myogenic differentiation-associated miRNAs and their target genes. BMC Genomics 14:265

Drummond MJ, McCarthy JJ, Sinha M, Spratt HM, Volpi E, Esser KA, Rasmussen BB (2011) Aging and microRNA expression in human skeletal muscle: a microarray and bioinformatics analysis. Physiol Genomics 43:595-603

Dumont NA, Bentzinger CF, Sincennes MC, Rudnicki MA (2015) Satellite cells and skeletal muscle regeneration. Compr Physiol 5:1027-1059

Egan B, Zierath JR (2013) Exercise metabolism and the molecular regulation of skeletal muscle adaptation. Cell Metab 17:162-184

Eisenberg I, Eran A, Nishino I, Moggio M, Lamperti C, Amato AA, Lidov HG, Kang PB, North KN, Mitrani-Rosenbaum S, Flanigan KM, Neely LA, Whitney D, Beggs AH, Kohane IS, Kunkel LM (2007) Distinctive patterns of microRNA expression in primary muscular disorders. Proc Natl Acad Sci USA 104:17016-17021 
Feng Y, Niu LL, Wei W, Zhang WY, Li XY, Cao JH, Zhao SH (2013) A feedback circuit between miR-133 and the ERK1/2 pathway involving an exquisite mechanism for regulating myoblast proliferation and differentiation. Cell Death Dis 4:e934

Gallagher IJ, Scheele C, Keller P, Nielsen AR, Remenyi J, Fischer CP, Roder K, Babraj J, Wahlestedt C, Hutvagner G, Pedersen BK, Timmons JA (2010) Integration of microRNA changes in vivo identifies novel molecular features of muscle insulin resistance in type 2 diabetes. Genome Med 2:9

Gan Z, Rumsey J, Hazen BC, Lai L, Leone TC, Vega RB, Xie H, Conley KE, Auwerx J, Smith SR, Olson EN, Kralli A, Kelly DP (2013) Nuclear receptor/microRNA circuitry links muscle fiber type to energy metabolism. J Clin Invest 123:2564-2575

Glass DJ (2010) Signaling pathways perturbing muscle mass. Curr Opin Clin Nutr Metab Care 13:225-229

Goljanek-Whysall K, Sweetman D, Abu-Elmagd M, Chapnik E, Dalmay T, Hornstein E, Munsterberg A (2011) MicroRNA regulation of the paired-box transcription factor Pax 3 confers robustness to developmental timing of myogenesis. Proc Natl Acad Sci USA 108:11936-11941

Granjon A, Gustin M-P, Rieusset J, Lefai E, Meugnier E, Güller I, Cerutti C, Paultre C, Disse E, Rabasa-Lhoret R, Laville M, Vidal H, Rome S (2009) The microRNA signature in response to insulin reveals its implication in the transcriptional action of insulin in human skeletal muscle and the role of a sterol regulatory element-binding protein-1c/myocyte enhancer factor $2 \mathrm{C}$ pathway. Diabetes 58:2555-2564

Greco S, De Simone M, Colussi C, Zaccagnini G, Fasanaro P, Pescatori M, Cardani R, Perbellini R, Isaia E, Sale P, Meola G, Capogrossi MC, Gaetano C, Martelli F (2009) Common microRNA signature in skeletal muscle damage and regeneration induced by Duchenne muscular dystrophy and acute ischemia. FASEB J 23:3335-3346

Guess MG, Barthel KK, Harrison BC, Leinwand LA (2015) miR-30 family microRNAs regulate myogenic differentiation and provide negative feedback on the microRNA pathway. PLoS One 10:e0118229

Hammond SM, Bernstein E, Beach D, Hannon GJ (2000) An RNA-directed nuclease mediates post-transcriptional gene silencing in Drosophila cells. Nature 404:293-296

Hasty P, Bradley A, Morris JH, Edmondson DG, Venuti JM, Olson EN, Klein WH (1993) Muscle deficiency and neonatal death in mice with a targeted mutation in the myogenin gene. Nature 364:501-506

He A, Zhu L, Gupta N, Chang Y, Fang F (2007a) Overexpression of micro ribonucleic acid 29, highly up-regulated in diabetic rats, leads to insulin resistance in 3T3-L1 adipocytes. Mol Endocrinol 21:2785-2794

He L, He X, Lowe SW, Hannon GJ (2007b) microRNAs join the p53 network-another piece in the tumour-suppression puzzle. Nat Rev Cancer 7:819-822

Herrera BM, Lockstone HE, Taylor JM, Ria M, Barrett A, Collins S, Kaisaki P, Argoud K, Fernandez C, Travers ME, Grew JP, Randall JC, Gloyn AL, Gauguier D, McCarthy MI, Lindgren CM (2010) Global microRNA expression profiles in insulin target tissues in a spontaneous rat model of type 2 diabetes. Diabetologia 53:1099-1109

Hitachi K, Nakatani M, Tsuchida K (2014) Myostatin signaling regulates Akt activity via the regulation of miR-486 expression. Intl J. Biochem Cell Biol 47:93-103

Huang B, Qin W, Zhao B, Shi Y, Yao C, Li J, Xiao H, Jin Y (2009) MicroRNA expression profiling in diabetic GK rat model. Acta Biochim Biophys Sin 41:472-477

Hudson MB, Woodworth-Hobbs ME, Zheng B, Rahnert JA, Blount MA, Gooch JL, Searles CD, Price SR (2014) miR-23a is decreased during muscle atrophy by a mechanism that includes calcineurin signaling and exosome-mediated export. Am J Physiol Cell Physiol 306:C551-C558

Hutvagner G, McLachlan J, Pasquinelli AE, Balint E, Tuschl T, Zamore PD (2001) A cellular function for the RNA-interference enzyme Dicer in the maturation of the let-7 small temporal RNA. Science 293:834-838

Karolina DS, Armugam A, Tavintharan S, Wong MT, Lim SC, Sum CF, Jeyaseelan K (2011) MicroRNA 144 impairs insulin signaling by inhibiting the expression of insulin receptor substrate 1 in type 2 diabetes mellitus. PLoS One 6:e22839 
Keller P, Vollaard NBJ, Gustafsson T, Gallagher IJ, Sundberg CJ, Rankinen T, Britton SL, Bouchard C, Koch LG, Timmons JA (2011) A transcriptional map of the impact of endurance exercise training on skeletal muscle phenotype. J Appl Physiol 110:46-59

Kim HK, Lee YS, Sivaprasad U, Malhotra A, Dutta A (2006) Muscle-specific microRNA miR-206 promotes muscle differentiation. J Cell Biol 174:677-687

Koning M, Werker PM, van Luyn MJ, Krenning G, Harmsen MC (2012) A global downregulation of microRNAs occurs in human quiescent satellite cells during myogenesis. Differentiation 84:314-321

Kovanda A, Režen T, Rogelj B (2014) MicroRNA in skeletal muscle development, growth, atrophy, and disease. Wiley Interdiscip Rev RNA 5:509-525

Krook A, Bjornholm M, Galuska D, Jiang XJ, Fahlman R, Myers MG Jr, Wallberg-Henriksson H, Zierath JR (2000) Characterization of signal transduction and glucose transport in skeletal muscle from type 2 diabetic patients. Diabetes 49:284-292

Lee RC, Feinbaum RL, Ambros V (1993) The C. elegans heterochronic gene lin-4 encodes small RNAs with antisense complementarity to lin-14. Cell 75:843-854

Lee Y, Ahn C, Han J, Choi H, Kim J, Yim J, Lee J, Provost P, Radmark O, Kim S, Kim VN (2003) The nuclear RNase III Drosha initiates microRNA processing. Nature 425:415-419

Liu N, Bezprozvannaya S, Williams AH, Qi X, Richardson JA, Bassel-Duby R, Olson EN (2008) microRNA-133a regulates cardiomyocyte proliferation and suppresses smooth muscle gene expression in the heart. Genes Dev 22:3242-3254

Liu N, Bezprozvannaya S, Shelton JM, Frisard MI, Hulver MW, McMillan RP, Wu Y, Voelker KA, Grange RW, Richardson JA, Bassel-Duby R, Olson EN (2011) Mice lacking microRNA 133a develop dynamin 2-dependent centronuclear myopathy. J Clin Invest 121:3258-3268

Liu N, Williams AH, Maxeiner JM, Bezprozvannaya S, Shelton JM, Richardson JA, Bassel-Duby R, Olson EN (2012) microRNA-206 promotes skeletal muscle regeneration and delays progression of Duchenne muscular dystrophy in mice. J Clin Invest 122:2054-2065

Lu H, Buchan RJ, Cook SA (2010) MicroRNA-223 regulates Glut4 expression and cardiomyocyte glucose metabolism. Cardiovasc Res 86:410-420

Massart J, Katayama M, Krook A (2016) microManaging glucose and lipid metabolism in skeletal muscle: role of microRNAs. Biochim Biophys Acta 1861:2130-2138

McCarthy JJ, Esser KA, Andrade FH (2007) MicroRNA-206 is overexpressed in the diaphragm but not the hindlimb muscle of mdx mouse. Am J Physiol Cell Physiol 293:C451-C457

McCarthy JJ, Esser KA, Peterson CA, Dupont-Versteegden EE (2009) Evidence of MyomiR network regulation of beta-myosin heavy chain gene expression during skeletal muscle atrophy. Physiol Genomics 39:219-226

Melo CA, Melo SA (2014) Biogenesis and physiology of microRNAs. In: Fabbri M (ed) Noncoding RNAs and cancer. Springer, New York, pp 5-24

Mohamed JS, Hajira A, Pardo PS, Boriek AM (2014) MicroRNA-149 inhibits PARP-2 and promotes mitochondrial biogenesis via SIRT-1/PGC-1 $\alpha$ network in skeletal muscle. Diabetes 63:1546-1559

Nicolas FE, Pais H, Schwach F, Lindow M, Kauppinen S, Moulton V, Dalmay T (2008) Experimental identification of microRNA-140 targets by silencing and overexpressing miR140. RNA 14:2513-2520

Nielsen S, Scheele C, Yfanti C, Åkerström T, Nielsen AR, Pedersen BK, Laye M (2010) Muscle specific microRNAs are regulated by endurance exercise in human skeletal muscle. J Physiol 588:4029-4037

O'Rourke JR, Georges SA, Seay HR, Tapscott SJ, McManus MT, Goldhamer DJ, Swanson MS, Harfe BD (2007) Essential role for Dicer during skeletal muscle development. Dev Biol 311:359-368

Oustanina S, Hause G, Braun T (2004) Pax7 directs postnatal renewal and propagation of myogenic satellite cells but not their specification. EMBO J 23:3430-3439

Petrella JK, Kim JS, Cross JM, Kosek DJ, Bamman MM (2006) Efficacy of myonuclear addition may explain differential myofiber growth among resistance-trained young and older men and women. Am J Physiol Endocrinol Metab 291:E937-E946 
Petrella JK, Kim JS, Mayhew DL, Cross JM, Bamman MM (2008) Potent myofiber hypertrophy during resistance training in humans is associated with satellite cell-mediated myonuclear addition: a cluster analysis. J Appl Physiol (1985) 104:1736-1742

Rao PK, Kumar RM, Farkhondeh M, Baskerville S, Lodish HF (2006) Myogenic factors that regulate expression of muscle-specific microRNAs. Proc Natl Acad Sci USA 103:8721-8726

Reinhart BJ, Slack FJ, Basson M, Pasquinelli AE, Bettinger JC, Rougvie AE, Horvitz HR, Ruvkun G (2000) The 21-nucleotide let-7 RNA regulates developmental timing in Caenorhabditis elegans. Nature 403:901-906

Rivas DA, Lessard SJ, Rice NP, Lustgarten MS, So K, Goodyear LJ, Parnell LD, Fielding RA (2014) Diminished skeletal muscle microRNA expression with aging is associated with attenuated muscle plasticity and inhibition of IGF-1 signaling. FASEB J 28:4133-4147

Rudnicki MA, Schnegelsberg PN, Stead RH, Braun T, Arnold HH, Jaenisch R (1993) MyoD or Myf-5 is required for the formation of skeletal muscle. Cell 75:1351-1359

Russell AP, Lamon S, Boon H, Wada S, Güller I, Brown EL, Chibalin AV, Zierath JR, Snow RJ, Stepto N, Wadley GD, Akimoto T (2013) Regulation of miRNAs in human skeletal muscle following acute endurance exercise and short-term endurance training. J Physiol 591:4637-4653

Ryder JW, Yang J, Galuska D, Rincon J, Bjornholm M, Krook A, Lund S, Pedersen O, WallbergHenriksson H, Zierath JR, Holman GD (2000) Use of a novel impermeable biotinylated photolabeling reagent to assess insulin- and hypoxia-stimulated cell surface GLUT4 content in skeletal muscle from type 2 diabetic patients. Diabetes 49:647-654

Sambasivan R, Yao R, Kissenpfennig A, Van Wittenberghe L, Paldi A, Gayraud-Morel B, Guenou H, Malissen B, Tajbakhsh S, Galy A (2011) Pax7-expressing satellite cells are indispensable for adult skeletal muscle regeneration. Development 138:3647-3656

Sempere LF, Freemantle S, Pitha-Rowe I, Moss E, Dmitrovsky E, Ambros V (2004) Expression profiling of mammalian microRNAs uncovers a subset of brain-expressed microRNAs with possible roles in murine and human neuronal differentiation. Genome Biol 5:R13

Sjögren RJ, Egan B, Katayama M, Zierath JR, Krook A (2015) Temporal analysis of reciprocal miRNA-mRNA expression patterns predicts regulatory networks during differentiation in human skeletal muscle cells. Physiol Genomics 47:45-57

Sokol NS, Ambros V (2005) Mesodermally expressed Drosophila microRNA-1 is regulated by twist and is required in muscles during larval growth. Genes Dev 19:2343-2354

Sweetman D, Goljanek K, Rathjen T, Oustanina S, Braun T, Dalmay T, Munsterberg A (2008) Specific requirements of MRFs for the expression of muscle specific microRNAs, miR-1, miR206 and miR-133. Dev Biol 321:491-499

Tremblay P, Dietrich S, Mericskay M, Schubert FR, Li Z, Paulin D (1998) A crucial role for Pax3 in the development of the hypaxial musculature and the long-range migration of muscle precursors. Dev Biol 203:49-61

van Rooij E, Quiat D, Johnson BA, Sutherland LB, Qi X, Richardson JA, Kelm RJ Jr, Olson EN (2009) A family of microRNAs encoded by myosin genes governs myosin expression and muscle performance. Dev Cell 17:662-673

Wada S, Kato Y, Okutsu M, Miyaki S, Suzuki K, Yan Z, Schiaffino S, Asahara H, Ushida T, Akimoto T (2011) Translational suppression of atrophic regulators by microRNA-23a integrates resistance to skeletal muscle atrophy. J Biol Chem 286:38456-38465

Wightman B, Ha I, Ruvkun G (1993) Posttranscriptional regulation of the heterochronic gene lin14 by lin- 4 mediates temporal pattern formation in C. elegans. Cell 75:855-862

Williams AH, Liu N, van Rooij E, Olson EN (2009a) MicroRNA control of muscle development and disease. Curr Opin Cell Biol 21:461-469

Williams AH, Valdez G, Moresi V, Qi X, McAnally J, Elliott JL, Bassel-Duby R, Sanes JR, Olson EN (2009b) MicroRNA-206 delays ALS progression and promotes regeneration of neuromuscular synapses in mice. Science 326:1549-1554

Wolfe RR (2006) The underappreciated role of muscle in health and disease. Am J Clin Nutr $84: 475-482$ 
Wu R, Li H, Zhai L, Zou X, Meng J, Zhong R, Li C, Wang H, Zhang Y, Zhu D (2015) MicroRNA-431 accelerates muscle regeneration and ameliorates muscular dystrophy by targeting Pax 7 in mice. Nat Commun 6:7713

Xu J, Li R, Workeneh B, Dong Y, Wang X, Hu Z (2012) Transcription factor FoxO1, the dominant mediator of muscle wasting in chronic kidney disease, is inhibited by microRNA-486. Kidney Int 82:401-411

Zacharewicz E, Lamon S, Russell A (2013) MicroRNAs in skeletal muscle and their regulation with exercise, ageing, and disease. Front Physiol 4:266

Zacharewicz E, Della Gatta P, Reynolds J, Garnham A, Crowley T, Russell AP, Lamon S (2014) Identification of microRNAs linked to regulators of muscle protein synthesis and regeneration in young and old skeletal muscle. PLoS One 9:e114009

Zhang D, Li X, Chen C, Li Y, Zhao L, Jing Y, Liu W, Wang X, Zhang Y, Xia H, Chang Y, Gao X, Yan J, Ying H (2012) Attenuation of p38-mediated miR-1/133 expression facilitates myoblast proliferation during the early stage of muscle regeneration. PLoS One 7:e41478

Zhao Y, Ransom JF, Li A, Vedantham V, von Drehle M, Muth AN, Tsuchihashi T, McManus MT, Schwartz RJ, Srivastava D (2007) Dysregulation of cardiogenesis, cardiac conduction, and cell cycle in mice lacking miRNA-1-2. Cell 129:303-317

Open Access This chapter is licensed under the terms of the Creative Commons Attribution 4.0 International License (http://creativecommons.org/licenses/by/4.0/), which permits use, sharing, adaptation, distribution and reproduction in any medium or format, as long as you give appropriate credit to the original author(s) and the source, provide a link to the Creative Commons license and indicate if changes were made.

The images or other third party material in this chapter are included in the chapter's Creative Commons license, unless indicated otherwise in a credit line to the material. If material is not included in the chapter's Creative Commons license and your intended use is not permitted by statutory regulation or exceeds the permitted use, you will need to obtain permission directly from the copyright holder. 